\title{
Characterization and identification of in vitro metabolites of (-)-epicatechin using ultra-high performance liquid chromatography-mass spectrometry
}

\author{
Rui Jun Cai, Xiao Ling Yin*, Jing Liu, Da Xu Qin, Gui Zhen Zhao \\ Department of Pharmacy, The People's Hospital of Jiuquan, Jiuquan, GanSu 735000, China \\ *For correspondence: Email: 496014540@qq.com; Tel: +86-937-6982217
}

Sent for review: 4 June 2017

Revised accepted: 27 November 2017

\begin{abstract}
Purpose: To characterize and identify metabolites of (-)-epicatechin in microsomal fraction of rat hepatocytes (MFRHs).

Methods: A single incubation of (-)-epicatechin ( $1 \mathrm{~mL}, 50 \mu \mathrm{g} / \mathrm{mL})$ in MFRH $(0.5 \mathrm{mg} / \mathrm{mL})$ was used for the generation of metabolites. Thereafter, the sample was subjected to protein precipitation prior to analysis with ultra-high performance liquid chromatography coupled to linear ion-trap orbitrap mass spectrometry (UHPLC-LTQ-Orbitap MS).

Results: Nine metabolites of (-)-epicatechin were characterized on the basis of high resolution mass measurement, MS spectra and literature data. Based on their structures, the major metabolic routes of (-)-epicatechin in MFRHs were identified as hydroxylation, dihydroxylation and glycosylation.

Conclusion: This is the first report on metabolites of (-)-epicatechin in MFRHs, and it is helpful in gaining deeper insight into the metabolism of (-)-epicatechin in vivo. The results will also provide guidance in research on the pharmacokinetics of new drugs.
\end{abstract}

Keywords: (-)-Epicatechin, Metabolites, Hydroxylation, Dihydroxylation, Glycosylation, Rat liver microsomes, Pharmacokinetic studies

\begin{abstract}
This is an Open Access article that uses a funding model which does not charge readers or their institutions for access and distributed under the terms of the Creative Commons Attribution License (http://creativecommons.org/licenses/by/4.0) and the Budapest Open Access Initiative (http://www.budapestopenaccessinitiative.org/read), which permit unrestricted use, distribution, and reproduction in any medium, provided the original work is properly credited.

Tropical Journal of Pharmaceutical Research is indexed by Science Citation Index (SciSearch), Scopus, International Pharmaceutical Abstract, Chemical Abstracts, Embase, Index Copernicus, EBSCO, African Index Medicus, JournalSeek, Journal Citation Reports/Science Edition, Directory of Open Access Journals (DOAJ), African Journal Online, Bioline International, Open-J-Gate and Pharmacy Abstracts
\end{abstract}

\section{INTRODUCTION}

(-)-Epicatechin and its isomer (+)-catechin, which belong to the flavan-3-ol family, are ubiquitously distributed in plants [1]. They have been used in many fields, such as food and medical industries due to their anti-oxidative [2], anti-microbial [3,4], and cardio-protective properties [5]. Research on the metabolism of drugs is a very important step in discovery of new drugs. It is also vital for drug development, pharmacokinetics, and clinical pharmaceutics [6]. However, not much is known about the metabolites of (-)-epicatechin [7]. On the other hand, more than 40 metabolites of the isomer of (-)-epicatechin, (+)-catechin have been isolated and characterized through in vitro and in vivo studies [8-11].

The technique of liquid chromatography coupled with mass spectrometry (LC-MS) is a useful tool for studying the metabolites of drugs in vitro or in vivo [12]. However, ultra-high performance liquid 
chromatography (UHPLC) can provide a higher and faster separation, and less solvent consumption than LC-MS [13], while highresolution mass spectrometry (HRMS) can provide elemental composition by accurate mass measurement. Therefore, UHPLC-HRMS has been widely used for the characterization of drug metabolites among several different LC/MS platforms [14-15].

The aim of this investigation was to isolate and characterize (-)-epicatechin metabolites from MFRHs.

\section{EXPERIMENTAL}

\section{Reagents}

Authentic (-)-epicatechin standard (purity $>98.0$ $\%$ was product of Chengdu Biopurify Phytochemicals Co, Ltd (Sichuan, China). Acetonitrile (HPLC grade) was purchased from Fisher Scientific (Fisher, Fair Lawn, USA). Reduced nicotinamide adenine dinucleotide phosphate (NADPH) was supplied by Zhong Sheng Rui Tai Biotech (Beijing, China), while a Milli-Q system (Millipore, MA, USA) was used for preparing distilled water. Rat liver microsomes were product of BD Biosciences (Bedford, MA, USA). Magnesium chloride and Tris-HCL buffer used in this experiment $(\mathrm{pH}$ 7.4) were of analytical grade.

\section{Incubation of microsomes}

Metabolic transformation was carried out in vitro in a final volume of $1 \mathrm{~mL}$ by incubating (-)epicatechin with RLMs in a shaking water bath at $37{ }^{\circ} \mathrm{C}$. (-)-Epicatechin $(50 \mu \mathrm{g} / \mathrm{mL})$ was preincubated for $5 \mathrm{~min}$ in $0.1 \mathrm{~mol} / \mathrm{L}$ Tris- $\mathrm{HCl}$ buffer (pH 7.4) containing $5 \mathrm{mM} \mathrm{MgCl} 2$ and $0.5 \mathrm{~g} / \mathrm{mL}$ MFRHs. Next, NADPH (1 mM) was added to initiate the reaction. The reaction was allowed to proceed for I h, and then stopped by introduction of ice-cold acetonitrile $(1 \mathrm{~mL})$ to the reaction mixture. The mixture was vortexed and clarified by centrifugation at $4{ }^{\circ} \mathrm{C}$ for $10 \mathrm{~min}$ at 15,000 rpm. The metabolites were identified by injection of $5 \mu \mathrm{L}$ of the supernatant into UHPLC-LTQOrbitrap MS. A solution prepared in a similar manner but lacking (-)-epicatechin served as blank. All analyses were done in triplicate.

\section{UHPLC-LTQ-Orbitrap analysis conditions}

All UHPLC-LTQ-Orbitrap analyses were performed with LTQ/Orbitrap XL hybrid mass spectrometer (Thermo Electron, Germany) equipped with An Accela UHPLC system (Thermo Fisher Scientific) comprising an auto sampler, a de-gasser component and a quaternary pump, via an electrospray ionization source (ESI) (Thermo Electron, Bremen, Germany). Column chromatography was carried out at room temperature using an Acquity ${ }^{\mathrm{TM}}$ UPLC BEH C18 column $(2.1 \times 50 \mathrm{~mm}, 1.7 \mu \mathrm{m})$ with a mobile phase of water (solvent $A$ ) and acetonitrile (solvent $\mathrm{B}$ ) through gradient elution (0.2mL per $/ \mathrm{min})$ as follows: $0.2 \mathrm{~mL} / \mathrm{min}: 0-2$ min, maintained at $5 \% \mathrm{~B} ; 2-3 \mathrm{~min}$, increased from 5 to $10 \% \mathrm{~B} ; 3-15 \mathrm{~min}$, increased from 10 to $15 \% \mathrm{~B} ; 15-17 \mathrm{~min}$, increased from 15 to 80 $\%$ B; $17-23$ min, maintained at $80 \%$ B; $23-24$ $\mathrm{min}$, decreased from 80 to $5 \% \mathrm{~B} ; 24-28 \mathrm{~min}$, maintained at $5 \% \mathrm{~B}$.

Negative ion mode was used in the MS/MS operations, and mass analysis was carried out at a resolution of 30,000 in the range of 100 to 800 $\mathrm{m} / \mathrm{z}$. The capillary voltage, source voltage, capillary temperature, tube lens sheath gas flow and auxiliary gas flow rate were $35 \mathrm{~V}, 3.0 \mathrm{kV}$, $350{ }^{\circ} \mathrm{C}, 110 \mathrm{~V}, 30$ and 10 arbitrary units, respectively.

\section{Data processing}

Data acquisition and processing were performed with Thermo X caliber 2.1 workstation (Thermo Fisher Scientific), and the results were compared with that from blank MFRH samples obtained under identical conditions.

\section{RESULTS}

\section{Metabolic routes of (-)-epicatechin}

In order to identify the metabolites of (-)epicatechin, the first step of this work was to study the $\mathrm{MS}^{2}$ fragmentation pattern of $(-)$ epicatechin. The parent ion $[\mathrm{M}-\mathrm{H}]$ ] was at $\mathrm{m} / \mathrm{z}$ 289.0704 ( $-0.9 \mathrm{ppm}, \mathrm{C}_{15} \mathrm{H}_{13} \mathrm{O}_{6}$ ) and the $\mathrm{MS}^{2}$ spectrum yielded fragment ions at $\mathrm{m} / \mathrm{z} 245.0811$ (1.1 ppm, $\quad \mathrm{C}_{14} \mathrm{H}_{13} \mathrm{O}_{4}$ ), m/z 205.0499 (1.8 ppm, $\left.\mathrm{C}_{11} \mathrm{H}_{9} \mathrm{O}_{4}\right)$ and $\mathrm{m} / z 179.0346\left(4.0 \mathrm{ppm}, \mathrm{C}_{9} \mathrm{H}_{7} \mathrm{O}_{4}\right)$ by loss of $\mathrm{CO}_{2}$ moiety $(44 \mathrm{Da}), \mathrm{C}_{4} \mathrm{H}_{4} \mathrm{O}_{2}(84 \mathrm{Da})$, and $\mathrm{C}_{6} \mathrm{H}_{6} \mathrm{O}_{2}(110 \mathrm{Da})$ (Figure 1). These product ions aided the identification of the metabolites of (-)-epicatechin.

\section{Identified metabolites}

The results from high resolution extracted ion chromatography (HREIC) are shown in Figure 2. Nine metabolites of (-)-epicatechin were tentatively characterized on the bases of high resolution mass measurements, MS spectra, and literature data in negative ion mode. The UPLCMS data are summarized in Table 1. 
Metabolite M0 was confirmed as (-)-epicatechin through comparison of the retention time, high resolution mass measurements, and $\mathrm{MS}^{2}$ spectra with authentic references.

Metabolites M3, M6, M8 and M9 eluted at 7.59, $12.53,14.53$, and $16.87 \mathrm{~min}$, respectively, and possessed un-protonated molecular ion $[\mathrm{M}-\mathrm{H}]^{-}$at $\mathrm{m} / \mathrm{z} 305.0652 \quad\left(-1.3 \quad \mathrm{ppm}, \quad \mathrm{C}_{15} \mathrm{H}_{13} \mathrm{O}_{7}\right), \quad \mathrm{m} / \mathrm{z}$ $305.0655\left(0 \mathrm{ppm}, \mathrm{C}_{15} \mathrm{H}_{13} \mathrm{O}_{7}\right), \mathrm{m} / \mathrm{z} 305.0654(-0.7$ ppm, $\mathrm{C}_{15} \mathrm{H}_{13} \mathrm{O}_{7}$ ), and $\mathrm{m} / \mathrm{z} 305.0651$ (-1.7 ppm, $\left.\mathrm{C}_{15} \mathrm{H}_{13} \mathrm{O}_{7}\right)$. These ions were by $16 \mathrm{Da}$ higher than that of (-)-epicatechin, implying that they were derived from (-)-epicatechin by hydroxylation. The diagnostic product ions at $\mathrm{m} / \mathrm{z} 179.0342$ (1.8 ppm, $\left.\mathrm{C}_{9} \mathrm{H}_{7} \mathrm{O}_{4}\right), \quad \mathrm{m} / \mathrm{z} 179.0337 \quad(-1.0 \mathrm{ppm}$, $\left.\mathrm{C}_{9} \mathrm{H}_{7} \mathrm{O}_{4}\right), \mathrm{m} / \mathrm{z} 179.0342$ (1.8 ppm, $\mathrm{C}_{9} \mathrm{H}_{7} \mathrm{O}_{4}$ ), and $\mathrm{m} / \mathrm{z} 179.0342$ (1.8 ppm, $\mathrm{C}_{9} \mathrm{H}_{7} \mathrm{O}_{4}$ ) were observed

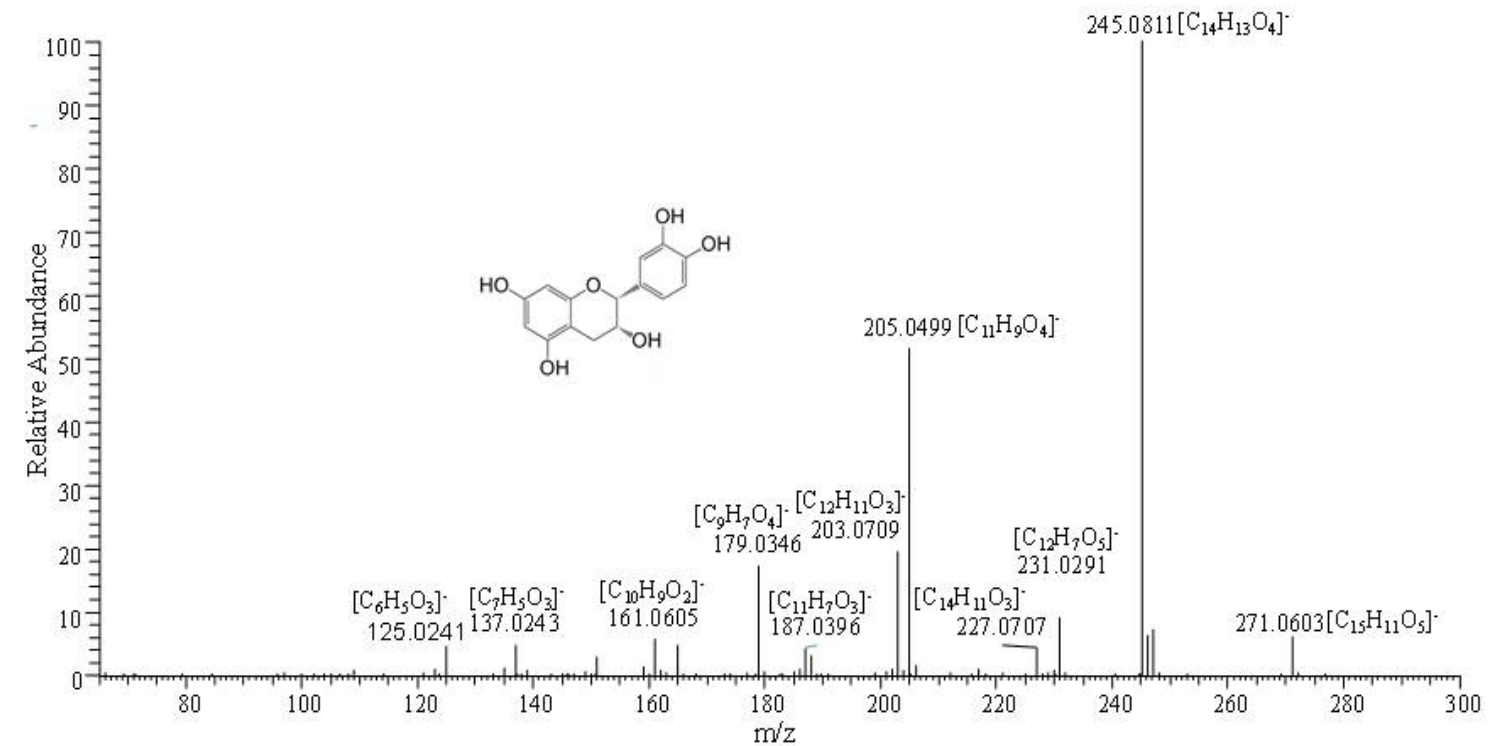

Figure 1: $\mathrm{MS}^{2}$ spectrum of (-)-epicatechin

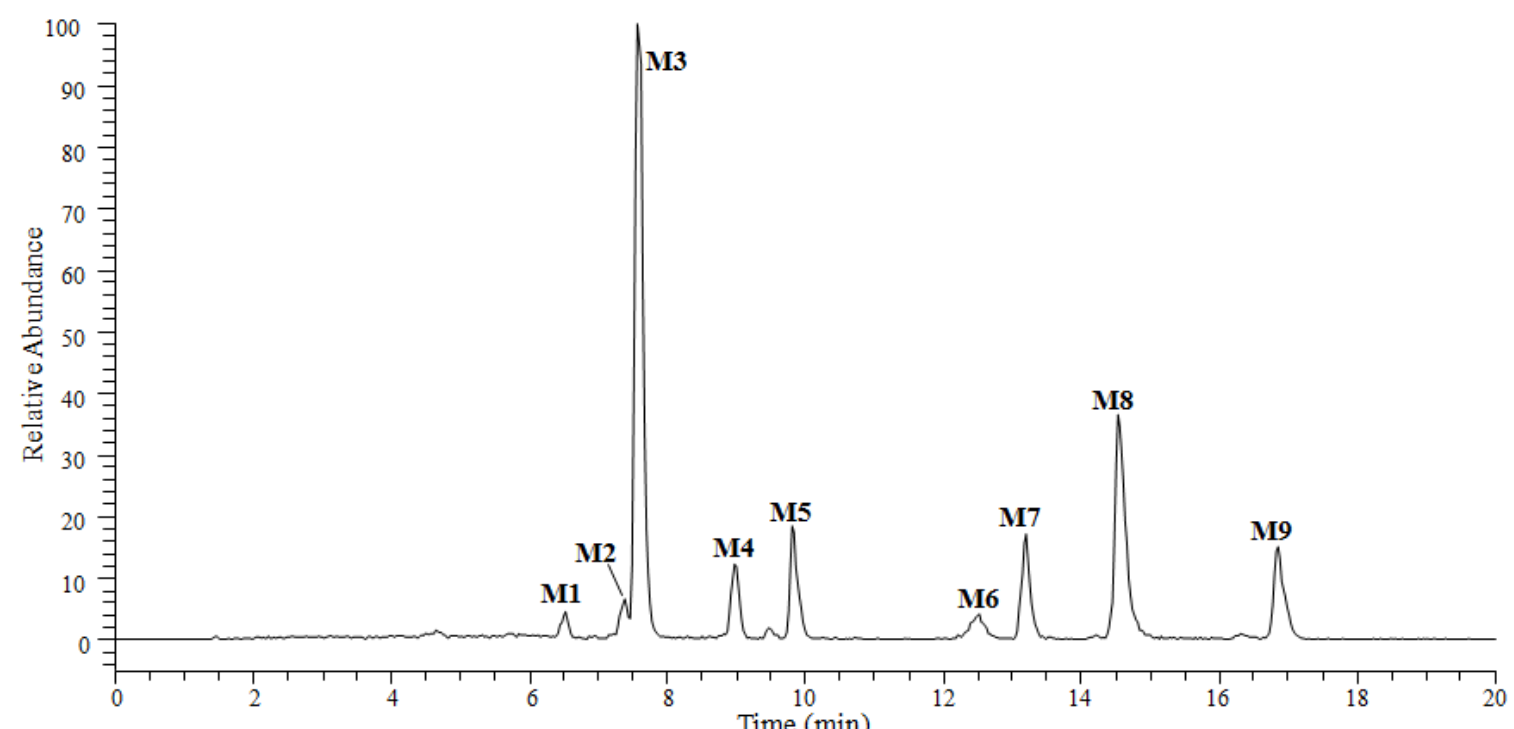

Figure 2: Results of HREIC analysis of (-)-epicatechin metabolites in MFRHs: $\mathrm{m} / \mathbf{z} 305.0655,331.0812$, 451.1235 in their $\mathrm{MS}^{2}$ spectra, which confirmed that they were metabolites of (-)-epicatechin. Therefore, they were tentatively characterized as hydroxylated products of (-)-epicatechin.

The compounds M1 and M2 were eluted at 6.54 and $7.38 \mathrm{~min}$ with the same deprotonated molecules at $\mathrm{m} / \mathrm{z} 331.0806\left(-1.9 \mathrm{ppm}, \mathrm{C}_{17} \mathrm{H}_{15} \mathrm{O}_{7}\right)$, which was a $+36 \mathrm{Da}(2 \mathrm{O})$-shift from that of (-)epicatechin. The MS2 spectra of M1 and M2 showed the major fragment ions at $\mathrm{m} / \mathrm{z} 313, \mathrm{~m} / \mathrm{z}$ 287 , and $m / z 269$, due to loss of $\mathrm{H}_{2} \mathrm{O}, \mathrm{CO}_{2}$, and $\mathrm{H}_{2} \mathrm{O}+\mathrm{CO}_{2}$, respectively from the parent drug which had similar fragmentation pattern with (-)epicatechin. Based on previous analyses, they were identified as dihydroxylated products of (-)epicatechin. 
Table 1: Fragment ions from (-)-epicatechin metabolism in MFRHs identified by UHPLC-LTQ-Orbitrap MS

\begin{tabular}{|c|c|c|c|c|c|c|c|}
\hline Peak & $t_{R}$ & $\begin{array}{l}\text { Theoretical mass } \\
\mathrm{m} / \mathrm{z}\end{array}$ & $\begin{array}{l}\text { Experimental mass } \\
\mathrm{m} / \mathrm{z}\end{array}$ & $\begin{array}{l}\text { Error } \\
\text { (ppm) }\end{array}$ & $\begin{array}{l}\text { Formula [M- } \\
\text { H] }^{-}\end{array}$ & MS/MS fragment & Transformation \\
\hline 1 & 6.54 & 331.0812 & 331.0806 & -1.9 & $\mathrm{C}_{17} \mathrm{H}_{15} \mathrm{O}_{7}$ & $\mathrm{MS}^{2}$ [331]: 313.0700 (100), 287.0910 (49), 269.0794 (32), 205.0495 (22) & Dihydroxylation \\
\hline 2 & 7.38 & 331.0812 & 331.0806 & -1.9 & $\mathrm{C}_{17} \mathrm{H}_{15} \mathrm{O}_{7}$ & $\mathrm{MS}^{2}$ [331]: 313.0699 (100), 287.0909 (49), 269.0798 (38), 205.0498 (16) & Dihydroxylation \\
\hline $\begin{array}{l}3 \\
4 \\
5\end{array}$ & $\begin{array}{l}7.59 \\
8.97 \\
9.82\end{array}$ & $\begin{array}{l}305.0655 \\
451.1235 \\
451.1235\end{array}$ & $\begin{array}{l}305.0652 \\
451.1230 \\
451.1229\end{array}$ & $\begin{array}{l}-1.3 \\
-1.2 \\
-1.4\end{array}$ & $\begin{array}{l}\mathrm{C}_{15} \mathrm{H}_{13} \mathrm{O}_{7} \\
\mathrm{C}_{21} \mathrm{H}_{23} \mathrm{O}_{11} \\
\mathrm{C}_{21} \mathrm{H}_{23} \mathrm{O}_{11}\end{array}$ & $\begin{array}{l}\mathrm{MS}^{2}[305]: 179.0342(100), 221.0444(76), 219.0651(74) \\
\mathrm{MS}^{2}[451]: 313.0700(100), 355.0803(63), 289.0701(8) \\
\mathrm{MS}^{2}[451]: 313.0911(100), 289.0701(66), 245.0805(37)\end{array}$ & $\begin{array}{l}\text { Hydroxylation } \\
\text { Glycosylation } \\
\text { Glycosylation }\end{array}$ \\
\hline 0 & $\begin{array}{c}12.2 \\
9\end{array}$ & 289.0707 & 289.0704 & -0.9 & $\mathrm{C}_{15} \mathrm{H}_{13} \mathrm{O}_{6}$ & $\begin{array}{c}\mathrm{MS}^{2} \text { [209]: } 245.0500(100), 205.0810(40), 203.0709(19), 179.0345(15), \\
231.0291(9), 271.0603(6)\end{array}$ & (-)-epicatechin \\
\hline 6 & $\begin{array}{c}12.5 \\
3\end{array}$ & 305.0655 & 305.0655 & 0.0 & $\mathrm{C}_{15} \mathrm{H}_{13} \mathrm{O}_{7}$ & $\mathrm{MS}^{2}[305]: 179.0337(100), 219.0653(75), 221.0446(70)$ & Hydroxylation \\
\hline 7 & $\begin{array}{c}13.2 \\
0\end{array}$ & 451.1235 & 451.1228 & -1.6 & $\mathrm{C}_{21} \mathrm{H}_{23} \mathrm{O}_{11}$ & $\mathrm{MS}^{2}$ [451]: $289.0703(100), 245.0806(58)$ & Glycosylation \\
\hline 8 & $\begin{array}{c}14.5 \\
3\end{array}$ & 305.0655 & 305.0654 & -0.7 & $\mathrm{C}_{15} \mathrm{H}_{13} \mathrm{O}_{7}$ & $\mathrm{MS}^{2}$ [305]: $179.0342(100), 219.0652(76), 221.0445(72)$ & Hydroxylation \\
\hline 9 & $\begin{array}{c}16.8 \\
7\end{array}$ & 305.0655 & 305.0651 & -1.7 & $\mathrm{C}_{15} \mathrm{H}_{13} \mathrm{O}_{7}$ & $\mathrm{MS}^{2}[305]: 179.0342(100), 219.0650(79), 221.0443(74)$ & Hydroxylation \\
\hline
\end{tabular}


Compounds M4, M5, and M7 appeared after 8.97, 9.82 and 13.20 min with un-protonated [M$\mathrm{H}]^{-}$at $\mathrm{m} / z 451.1230\left(-1.2 \mathrm{ppm}, \mathrm{C}_{21} \mathrm{H}_{23} \mathrm{O}_{11}\right), \mathrm{m} / \mathrm{z}$ 451.1229 (-1.4 ppm, $\left.\mathrm{C}_{21} \mathrm{H}_{23} \mathrm{O}_{11}\right)$, and $\mathrm{m} / \mathrm{z}$ 451.1228 (-1.6 ppm, $\left.\mathrm{C}_{21} \mathrm{H}_{23} \mathrm{O}_{11}\right), 162 \mathrm{Da}$ $\left(\mathrm{C}_{6} \mathrm{H}_{10} \mathrm{O}_{5}\right)$ higher when compared with (-)epicatechin. Fragments at $\mathrm{m} / \mathrm{z} 289.0701 \quad(-2.0$ ppm, $\left.\quad \mathrm{C}_{15} \mathrm{H}_{13} \mathrm{O}_{6}\right), \quad \mathrm{m} / \mathrm{z} 289.0701 \quad(-2.0 \mathrm{ppm}$, $\left.\mathrm{C}_{15} \mathrm{H}_{13} \mathrm{O}_{6}\right)$, and $\mathrm{m} / \mathrm{z} 289.0703 \quad(-1.3 \mathrm{ppm}$, $\left.\mathrm{C}_{15} \mathrm{H}_{13} \mathrm{O}_{6}\right)$ by loss glucosyl $\left(\mathrm{C}_{6} \mathrm{H}_{10} \mathrm{O}_{5}, 121 \mathrm{Da}\right)$ moiety relative to the precursor ion at $\mathrm{m} / \mathrm{z} 451$ in their $\mathrm{MS}^{2}$ spectra indicated that a glucosyl moiety was present. Thus, they were presumed to be glucosyl products of (-)-epicatechin.

\section{DISCUSSION}

The results obtained from preliminary trials with various mobile phase systems in this study showed that good chromatographic peak shapes could be achieved by using mobile system without formic acid, while much lower column pressure was afforded by the inclusion of acetonitrile in the mobile phase. Therefore, the mixture of acetonitrile and water was chosen as the mobile phase solvent system in this study. A gradient elution pattern was adopted.

(-)-Epicatechin is characterized by the presence of many hydroxyl groups on the flavanol skeleton, which make it suitable for detection by ESI in negative mode [15]. To the best of our knowledge, many studies have so far focused mainly on the metabolites of (+)-catechin, while not much has been done on the elucidation of the metabolites of (-)-epicatechin. For example, 40 and 58 metabolites of $(+)$-catechin were found in in vitro and in vivo investigations, respectively [8-11]. Among these, 7 metabolites were identified in MFRHs [16]. It is worth mentioning that (-)-epicatechin has a metabolic pathway similar to that of $(+)$-catechin in MFRHs. Therefore, it is scientifically reasonable to assume that the in vivo metabolisms of (-)epicatechin and (+)-catechin will follow a similar route. This will be helpful in the identification of metabolic products of (-)-epicatechin in vivo.

\section{CONCLUSION}

The in vitro metabolites of (-)-epicatechin have been successfully identified based on UHPLCLTQ-Orbitrap analysis. Based on the 9 metabolites identified and their MS data, the major metabolic pathways of (-)-epicatechin in RLMs are hydroxylation, dihydroxylation and glycosylation. This is the first report on the metabolites of (-)-epicatechin in RLMs and is considered a useful guide for understanding its metabolism in vivo. In addition, the methodology used in this study offers a new perspective for studying the metabolism and pharmacokinetics of new drugs.

\section{DECLARATIONS}

\section{Acknowledgement}

The authors gratefully acknowledge $\mathrm{Dr}$ di Jia for supporting this project.

\section{Conflict of interest}

The authors declare that no conflict of interest is associated with this study.

\section{Contribution of authors}

We declare that this work was done by the authors named in this article and all liabilities pertaining to claims relating to the content of this article will be borne by the authors. Xiao Ling Yin planned and designed the research; Rui Jun Cai and Jing Liu performed the experiments, Ruijun Cai wrote the manuscript, while Da Xu Qin and Gui Zhen Zhao analyzed the data.

\section{REFERENCES}

1. Porter LJ. In The Flavonoids, Advances in Research since 1986; Harborne, J. B., Ed.; Chapman \& Hall: Landon, 1994; pp 23-56.

2. Abd El-Aziz TA, Mohamed RH, Pasha HF and Abdel-Aziz HR. Catechin protects against oxidative stress and inflammatory-mediated cardiotoxicity in adriamycintreated rats. Clin Exp Med 2012; 12: 233-240.

3. Dai CM, Wang JB, Kong WJ, Cheng $P$, Xiao XH. Investigation of anti-microbial activity of catechin on Escherichia coli growth by microcalorimetry. Environ Toxicol Phar 2010; 30(3): 284-288.

4. Rawdkuen $S$, Suthiluk $P$, Kamhangwong D, Benjakul $S$. Antimicrobial activity of some potential active compounds against food spoilage microorganisms. Afr J Biotechnol 2012; 11: 13914-13921.

5. Nagao T, Hase T, Tokimitsu I. A green tea extract high in catechins reduces body fat and cardiovascular risks in humans. Obesity 2007; 15(6): 1473-1483.

6. LaDu BN, Mandel HG, Way EL. (eds.). Fundamentals of Drug Metabolism and Drug Disposition, Baltimore: Williams \& Wilkins, 1971. pp. 569-572.

7. Harada M, Kan Y, Naoki H, Fukui Y, Kageyama N, Nakai $M$, Miki $W$ and Kiso $Y$. Identification of the major antioxidative metabolites in biological fluids of the rat with ingested (+)-catechin and (-)-epicatechin. Biosci Biotechnol Biochem 1999; 63: 973-977.

8. Liang J, Xu F, Zhang $Y Z$, Zang $X Y$, Wang D, Shang $M Y$, Wang $X$, Chui $D H$, Cai $S Q$. The profiling and identification of the metabolites of (+)-catechin and study 
on their distribution in rats by HPLC-DAD-ESI-IT-TOFMSn technique. Biomed Chromatogr 2014; 28(3): 401 411.

9. Das S, Lamm AS, Rosazza JPN. Biotransformation of (+)-Catechin to Novel B-Ring Fission Lactones. Org Process Res Dev 2011; 15: 231-235.

10. Alberto MR, Gomez-Cordoves C, Manca de Nadra MC. Metabolism of gallic acid and catechin by Lactobacillus hilgardii from wine. J Agric Food Chem 2004; 52: 64656469.

11. Das NP. Flavonoid metabolism. Absorption and metabolism of (+)-catechin in man. Biochem Pharmacol 1971; 20: 3435-3445.

12. Kachlicki P, Einhorn J, Muth D, Kerhoas L, Stobiecki M. Evaluation of glycosylation and malonylation patterns in flavonoid glycosides during LC/MS/MS metabolite profiling. J Mass Spectrom 2008; 43(5): 572-586.
13. Nováková L, Matysová L, Solich P. Advantages of application of UPLC in pharmaceutical analysis. Talanta 2006; 68(3): 908-918.

14. Cai W, Zhang JY, Liu SY, Lu JQ, Zhang HG. Metabolic profiles of $11,13 \alpha$-dihydroixerin $Z$ in rats using high performance liquid chromatography-LTQ-Orbitao mass spectrometry. Anal Method 2016; 8(4); 854-861

15. Cai RJ, Wei J, Jing FL, Zhao GZ, Zhang Y. Identification of metabolites of gardenin $A$ in rat liver microsomes using ultra-high performance liquid chromatography coupled with linear ion-trap Orbitrap mass spectrometry. Trop J Pharm Res 2017: 16(2): 421-427.

16. Liu GQ, Dong J, Wang H, Wan LR, Hashi Y, Chen SZ. ESI fragmentation studies of four tea catechins. Chem $J$ Chin Univ 2009; 30(8): 1566-1570.

17. Sun $\mathrm{JH}, \mathrm{Li} X R$. Identification of metabolites of (+)catechin in rat liver microsomes based on UPLC-LTQOrbitap and multiple mass defect filter method. Chin Hosp Pharm J 2016; 36(15): 1264-1267. 